\title{
EarthQuake Characteristics of Bridges with INTEGRAL Abutments
}

\author{
By Rakesh K. Goel
}

\begin{abstract}
Earthquake analysis of bridges requires that the period and damping ratio be determined for each significant mode of vibration. Data on these vibration properties, identified from motions of bridges recorded during actual earthquake events, provide the most direct means of verifying and improving the current guidelines. Thus, the aim of this investigation was to measure the vibration properties of a two-span concrete bridge from its motions recorded during actual earthquake events. These data were then used to investigate how abutment participation affected the vibration properties of bridges with integral abutments. It is shown that the vibration period elongated and the damping ratio increased by a factor of over two as the intensity of ground shaking increased. These changes primarily were caused by increased abutment participation with increased intensity of shaking. Finally, the damping data were used to develop empirical formulas for estimating upper and lower bound values of damping in the first transverse vibration mode of bridges with integral abutments.
\end{abstract}

\section{INTRODUCTION}

Most specifications and guidelines for design of highway bridges require that earthquake design forces be computed by the elastic response spectrum procedure [Applied Technology Council (ATC)-6 1981; American Association of State Highway Transportation Officials (AASHTO)-83 1988; CALTRANS 1991)]. This procedure requires estimation of two vibration properties in each significant mode: the period and the damping ratio. Estimation of the vibration properties of bridges with integral abutments is not as simple as it may appear. Generally, vibration periods of a system may be calculated from its stiffness and mass properties. For bridges, difficulties arise primarily because of the lack of accurate procedures to estimate stiffness of abutments. In general, abutment stiffness is determined by an iterative procedure based on simple rules (ATC-6 1981; AASHTO-83 1988; CALTRANS 1991). It is not clear if the estimated stiffness obtained from such procedures would lead to reasonable estimates of vibration periods. The calculation of vibration periods from the motions of bridges recorded during actual earthquake events provides a unique opportunity to verify these procedures. Recognizing such opportunity, several previous investigations were concerned with the estimation of vibration periods of bridges from their recorded motions (Gates and Smith 1982; Maroney et al. 1990; Ventura et al. 1995; Werner et al. $1987,1990)$. However, the motions used in these investigations were generally at a lower level of shaking, such as during small earthquakes or during field testing. There is need to develop a database for periods of bridges during strong shaking such as that expected during the design level earthquake.

Unlike vibration periods, damping properties cannot be calculated from structural dimensions, structural member sizes, and/or the damping properties of the structural material. For buildings, recommendations for damping properties were developed by Newmark and Hall (1982) based on judgment and on damping calculated from motions of buildings recorded during the 1971 San Fernando earthquake. However, for bridges, damping data have only recently become available and appropriate recommendations for the damping properties

Asst. Prof., Dept. of Civ. and Envir. Engrg., Syracuse Univ., Syracuse, NY 13244-1190; currently at Dept. of Civ. and Envir. Engrg., Cal Poly State Univ., San Luis Obispo, CA 93407. have not been developed. In the absence of such recommendations, a damping value of $5 \%$ of the critical value has been used in response spectrum analysis of bridges. However, several recent studies have indicated that damping occurs far in excess of the 5\% value (Werner et al. 1990; Tsai et al. 1993; Crouse and Werner 1995), especially for modes involving significant abutment participation. Therefore, there is a need to increase the database on damping properties of bridges and develop recommendations appropriate for design applications.

In this investigation, the vibration properties of a two-span concrete bridge were identified from its motions recorded during actual earthquake events. The identified properties included the vibration period, mode shape, and damping ratio in the first transverse mode, which involved significant abutment participation. These data were then used to investigate how abutment participation affected the vibration properties of bridges with integral abutments. A simple parameter was defined to quantify the participation of abutments in the earthquake response of such bridges. Subsequently, design implications of changes in the vibration properties because of abutment participation were examined. Finally, simple empirical formulas were developed to estimate damping in the first transverse vibration mode of bridges with integral abutment.

\section{STRUCTURE AND RECORDED MOTIONS}

The structure considered in this study is the U.S. 101/Painter Street Overpass (PSO) bridge (Fig. 1) located in Rio Dell, Calif. This 265 -ft-long bridge consists of a continuous reinforced concrete (RC) multicell box-girder road deck supported on integral abutments at the two ends and an RC two-column bent. The bent divides the bridge into two unequal spans of 119 and $146 \mathrm{ft}$. Both abutments and bent are skewed at an angle of $38.9^{\circ}$. This bridge is typical of short bridges in $\mathrm{Cal}$ ifornia that span two- or four-lane divided highways.

The abutment details for the PSO bridge are shown in Fig. 2. The east abutment is monolithic with the superstructure and is supported on 14 concrete friction piles, each with a capacity of 45 tons. However, the west abutment contains a thermal expansion joint between the abutment diaphragm and the pile cap. The joint consists of a grease-coated metal strip resting on a neoprene strip. The joint is designed to permit a 1-in. movement in both the longitudinal and the transverse direction; the gap between the abutment diaphragm and the shear keys on the pile cap is filled with expanded polystyrene. Soil is prevented from entering into the joint on the back and sides by an angle-shaped neoprene strip cemented to the abutment diaphragm. However, on the front side, the joint is buried in the berm. Structural drawings of the joint do not show any protection against soil entering into the joint from the front 


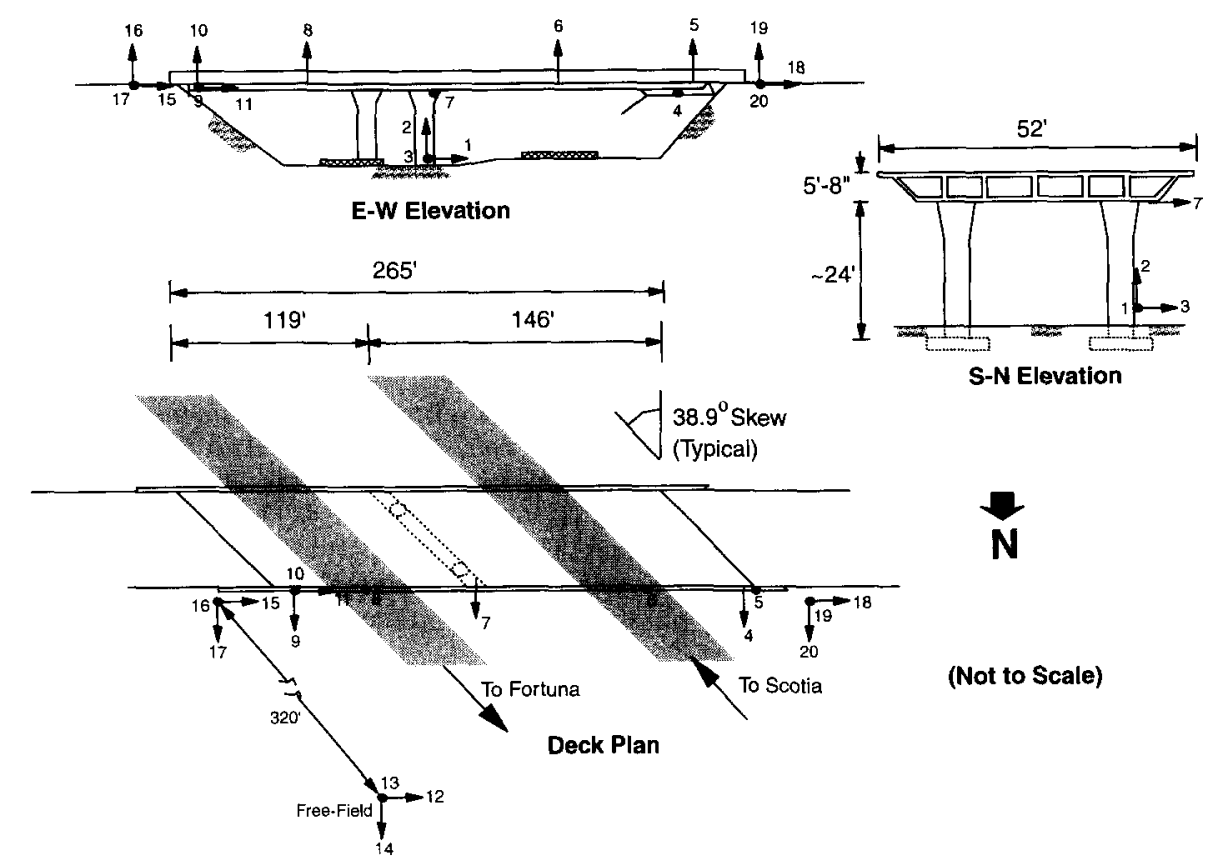

FIG. 1. PSO Structural Details and Sensor Locations

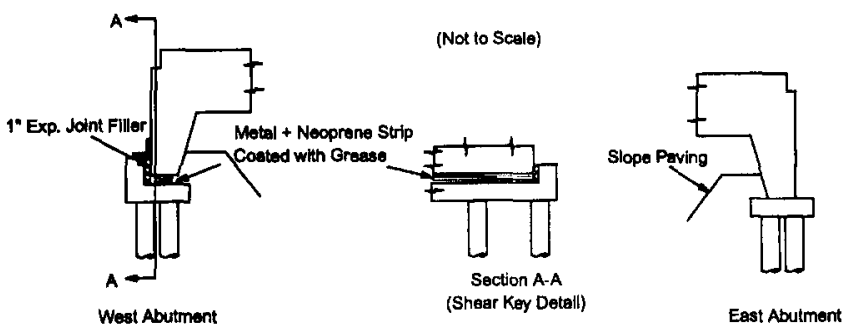

FIG. 2. Abutment Details for the PSO

side. The foundation of this abutment consists of 16 concrete friction piles.

The PSO bridge was instrumented by the California Strong Motion Instrumentation Program (CSMIP) in 1977. The locations of the sensors and 20 data channels also are shown in Fig. 1. Motions of this bridge have been recorded during several earthquakes; Table 1 lists nine earthquakes for which data were available at the time of this investigation. The strongest shaking at the bridge occurred during the main shock of the 1992 Cape Mendocino/Petrolia earthquake. During this earthquake, the peak free-field accelerations were 0.38 and $0.54 \mathrm{~g}$ in the longitudinal (channel 12) and transverse (channel 14) directions, respectively. These motions were amplified to $0.45 \mathrm{~g}$ in the longitudinal direction (channel 11) near the east end of the road deck and to $1.09 \mathrm{~g}$ in the transverse direction (channel 4) near the west end of the road deck. Postearthquake inspection reports, obtained from the CALTRANS, indicated that this bridge suffered no structural damage during these earthquakes.

The data presented in Table 1 show that transverse accelerations (N-S direction) near the east abutment (channel 9) exceeded those near the west abutment (channel 4) during earthquakes prior to the 1992 events. This contradicts the expected behavior that motions should be larger near the west abutment because of an expansion joint at that abutment; the expansion joint should provide little resistance to movement during an earthquake. From an analysis of the data, it appears that the joint was in locked condition and did not permit free movement during these earthquakes. Such a condition may have occurred because of frictional resistance that developed as a result of soil entering into the joint from the berm side. As mentioned previously, structural details of the joint do not indicate any preventive measure to guard against such a possibility. The frictional resistance also may have developed because of deterioration of the grease over time. For locked condition of the joint, the west abutment would be stiffer because of a larger number of piles in its foundation; the west and east abutments being supported on 16 and 14 piles, respectively. As a result, motions near the more flexible east abutment may be larger compared with the west abutment. Significantly

TABLE 1. List of Recorded Motions at U.S. 101/Painter Street Overpass

\begin{tabular}{|c|c|c|c|c|c|c|c|c|c|c|}
\hline \multirow[b]{3}{*}{$\begin{array}{l}\text { No. } \\
\text { (1) }\end{array}$} & \multirow[b]{3}{*}{$\begin{array}{c}\text { Earthquake } \\
\text { (2) }\end{array}$} & \multirow{3}{*}{$\begin{array}{l}\text { Depth } \\
\text { (km) } \\
(3)\end{array}$} & \multirow{3}{*}{$\begin{array}{c}\text { Magnitude } \\
M_{L} \\
\text { (4) }\end{array}$} & \multirow{3}{*}{$\begin{array}{l}\text { Epicentral } \\
\text { distance } \\
(\mathrm{km}) \\
(5)\end{array}$} & \multirow{2}{*}{\multicolumn{2}{|c|}{$\begin{array}{c}\text { MAXIMUM E-W } \\
\text { ACCELERATION } \\
(g) \\
\text { Channel No. }\end{array}$}} & \multirow{2}{*}{\multicolumn{4}{|c|}{$\begin{array}{l}\text { MAXIMUM N-S } \\
\text { ACCELERATION } \\
(g) \\
\text { Channel No. }\end{array}$}} \\
\hline & & & & & & & & & & \\
\hline & & & & & $\begin{array}{l}12 \\
(6)\end{array}$ & $\begin{array}{l}11 \\
(7)\end{array}$ & $\begin{array}{l}14 \\
(8)\end{array}$ & $\begin{array}{c}4 \\
(9)\end{array}$ & $\begin{array}{c}7 \\
(10)\end{array}$ & $\begin{array}{c}9 \\
(11)\end{array}$ \\
\hline 1 & Trinidad Offshore (Nov. 8, 1980) & 19 & 6.9 & 82 & 0.15 & 0.16 & 0.06 & - & - & 0.17 \\
\hline 2 & Rio Dell (Dec. 16, 1982) & 5 & 4.4 & 15 & - & 0.27 & - & 0.27 & 0.42 & 0.37 \\
\hline 3 & Eureka (Aug. 24, 1983) & 30 & 5.5 & 61 & - & 0.14 & - & 0.11 & 0.21 & 0.17 \\
\hline 4 & Cape Mendocino [Nov. 21, 1986 (1st event)] & 17 & 5.1 & 32 & 0.43 & 0.40 & 0.15 & 0.16 & 0.25 & 0.22 \\
\hline 5 & Cape Mendocino [Nov. 21, 1986 (2nd event)] & 18 & 5.1 & 26 & 0.14 & 0.18 & 0.12 & 0.21 & 0.35 & 0.30 \\
\hline 6 & Cape Mendocino (Jul. 31, 1987) & 17 & 5.5 & 28 & 0.14 & 0.21 & 0.09 & 0.17 & 0.33 & 0.24 \\
\hline 7 & Cape Mendocino/Petrolia (Apr. 25, 1992) & 15 & 6.4 & 24 & 0.38 & 0.45 & 0.54 & 1.09 & 0.86 & 0.69 \\
\hline 8 & Cape Mendocino/Petrolia [Apr. 26, 1992 (AS no. 1)] & 18 & 6.2 & 42 & 0.28 & 0.34 & 0.52 & 0.76 & 0.62 & 0.60 \\
\hline 9 & Cape Mendocino/Petrolia [Apr. 26, 1992 (AS no. 2)] & 21 & 6.4 & 41 & 0.26 & 0.31 & 0.20 & 0.31 & 0.30 & 0.26 \\
\hline
\end{tabular}


larger inertial forces experienced by the bridge during the main shock of the 1992 Cape Mendocino/Petrolia earthquake and its two aftershocks appeared to have unlocked the joint at the west abutment. As a result, the motions near the west abutment during these earthquakes were much larger.

The PSO bridge has been a subject of numerous investigations [e.g., Gates and Smith (1982); Maroney et al. (1990); Ventura et al. (1995); Goel and Chopra (1995, 1997)]. Various aspects of its dynamic behavior, either during field testing or during earthquakes, have been investigated. However, this paper will discuss results of only those investigations that specifically examined the vibration periods and/or damping ratios.

\section{IDENTIFICATION OF VIBRATION PROPERTIES}

Transverse vibration properties - fundamental period, mode shape, and damping ratio- of the PSO bridge were identified from its motions recorded during the 1986 and subsequent earthquakes. Also calculated was the contribution of abutments to earthquake motions of the bridge in the transverse direction. These properties could not be identified for earthquakes prior to the 1986 event because data needed for the system identification process could not be obtained from some of the channels. This section briefly describes the procedures used to calculate these properties.

\section{System Identification}

The modal minimization method (Beck 1978; Li and Mau 1991) was used to identify vibration periods, mode shapes, and damping ratios of the PSO bridge from its motions recorded during earthquakes. This multiinput and multioutput (MIMO) method is designed to estimate vibration properties of linear systems by minimizing the squared error between the

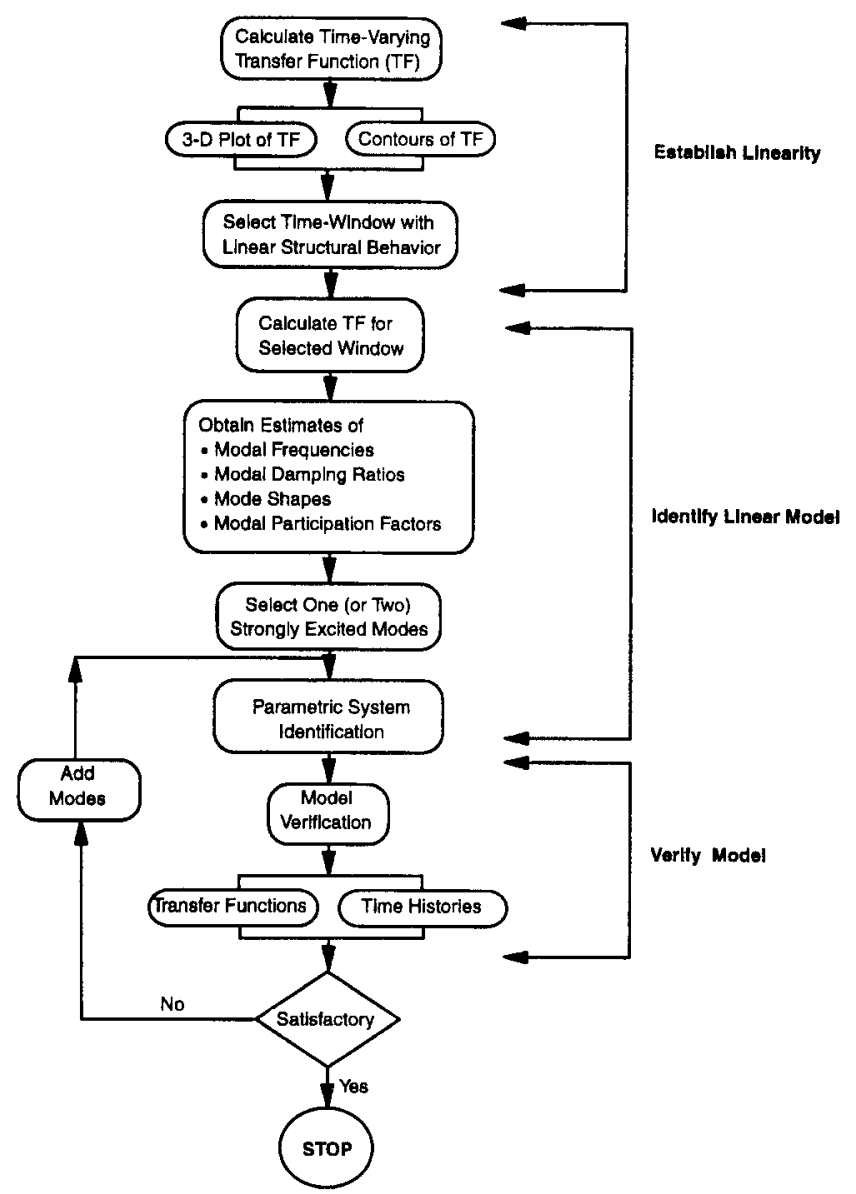

FIG. 3. Flowchart of the System Identification Procedure output and input accelerations for various vibration parameters of the structure. The transverse vibration properties of the PSO bridge were identified using transverse motions recorded at three locations on the bridge deck-channels 4,7 , and 9-as output from the system, and transverse motion recorded at the free field-channel 14-as input to the system.

The procedure to identify the vibration properties is summarized in the flowchart presented in Fig. 3. The procedure consists of the following two main steps: (1) Selection of time windows during which the bridge can be assumed to act as a linear system; and (2) identification of the vibration properties for the linear system including verification of the identified model.

\section{Selection of Time Windows}

Identification of the vibration properties of a bridge requires careful analysis of its recorded motions because of system nonlinearities. It has been observed (Goel and Chopra 1995) that bridges with integral abutments may respond in the nonlinear range because of nonlinearities at the abutment-soil-pile systems, even though other structural components remain elastic. As a result, the linear system identification technique may not be directly applicable to such bridges. However, this identification technique can be applied to those portions of recorded motions during which linear system behavior can be

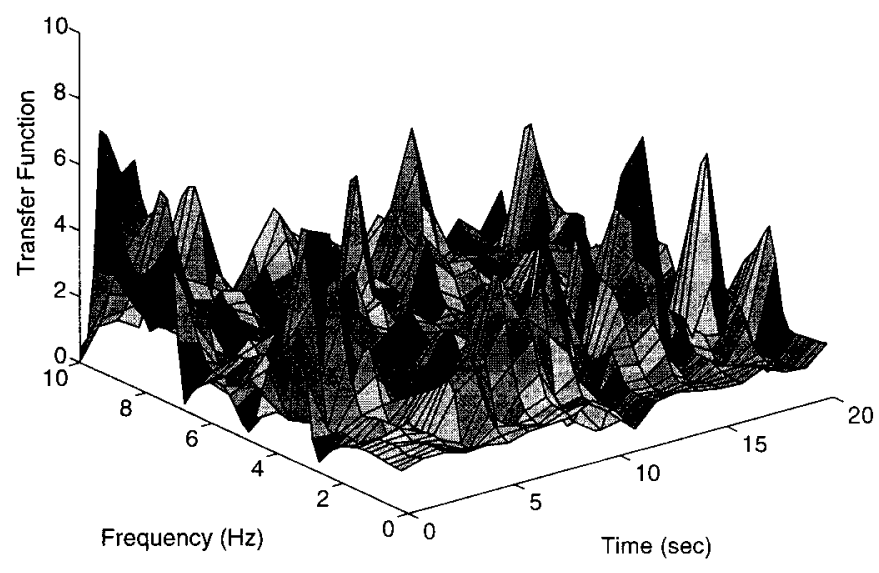

(a)

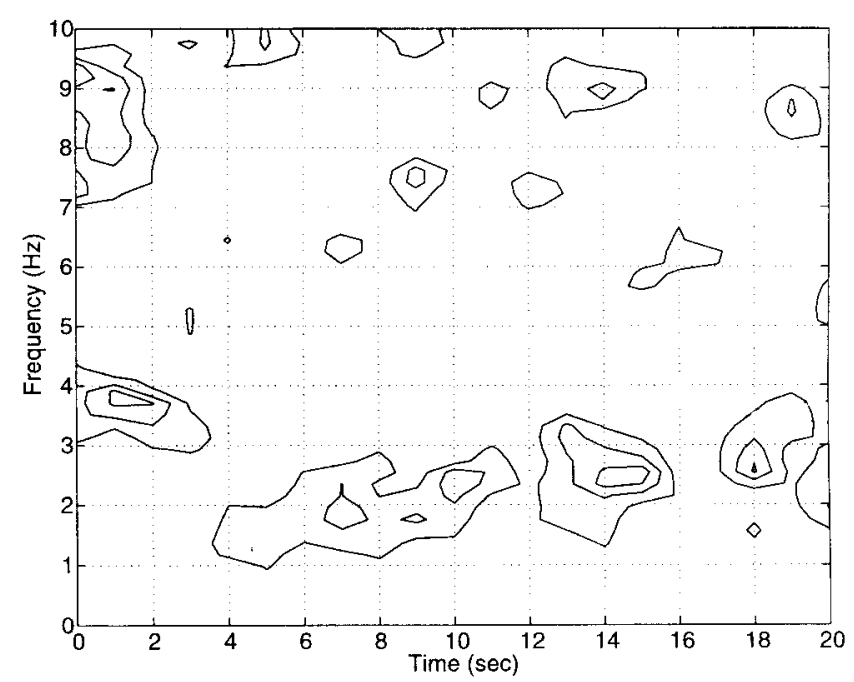

(b)

FIG. 4. Time-Varying Transfer Function for Motion Recorded at Channel 4 during Main Shock of 1992 Cape Mendocino/Petrolia Earthquake: (a) Three-Dimensional Plot; (b) Contours 
established. Because the vibration properties would obviously differ between various time windows depending on the degree of nonlinearity in the system, the selection of appropriate time windows is essential for proper identification of these properties.

The appropriate time windows were identified by examining time-varying transfer functions, such as the one shown in Fig. 4 for motions of the PSO bridge recorded at output channel 4 during the main shock of the 1992 Cape Mendocino/Petrolia earthquake. The value of the time-varying transfer function was obtained by stepping through the earthquake record with 2.56-s-long windows (128 data points). As shown in Fig. 4, during the first few seconds of shaking, fundamental vibration frequency of the bridge in the transverse direction was about $4 \mathrm{~Hz}$. This frequency dropped to about $1.75 \mathrm{~Hz}$ at $4 \mathrm{~s}$ and remained essentially unchanged until $8 \mathrm{~s}$. Subsequently, the frequency increased slowly to approximately $2.5 \mathrm{~Hz}$ as motions became less intense during the later part of the shaking. By examining this figure, it was possible to identify several time windows, such as 0-2 s, 4-8 s, and 12-16 s, during which the frequency remained essentially the same. Obviously, such time windows can be used for linear system identification. In this investigation, the time windows were selected by examining time-varying transfer functions for all output channels-channel 4, 7, and 9-used for system identification.

\section{Identification of Vibration Properties}

The vibration properties of the PSO bridge are identified by applying the MIMO system identification procedure to the selected time window. This procedure requires initial estimates of the modal parameters: frequency, damping ratio, participation factor, initial velocity, initial displacement, and modeshape components. In this investigation, initial estimates of the frequency, damping ratio, participation factor, and mode-shape components were obtained by examining the transfer functions of output motions, whereas initial velocity and displacement were taken as zero.

Once the initial estimates of the modal parameters were available, the vibration properties were identified through an iterative process. The process began with initial estimates of the modal parameters for one or two strongly excited modes. The system identification procedure refined these initial estimates by minimizing the error between the recorded motions and the model response in the least-squared sense. Thereafter, the identified model was verified by comparing transfer functions and time histories of the recorded motions with those of the identified model, such as those shown in Fig. 5. The iterative process is designed to end when a good match is obtained for the transfer function, as well as, the time history for each of the output channels. Otherwise, additional modes, one at a time, are included and the process is repeated until satisfactory results are obtained.

The example presented in Fig. 5 required only three modes to be included in the identification process. The final values of the first transverse frequency and damping ratio were 1.75 $\mathrm{Hz}$ and $8.5 \%$, respectively, compared with their initial estimates of $1.66 \mathrm{~Hz}$ and $5 \%$. Although there was considerable disagreement at higher frequencies [Fig. 5(a)], the two transfer functions matched reasonably well near the first transverse mode. Furthermore, there was good agreement between the two time histories [Fig. 5(b)]. Because the objective of this investigation was to identify the fundamental mode only, the identified model was considered acceptable.

It should be noted that damping ratio is a very sensitive parameter to estimate from motions of structures recorded during earthquakes because the linear viscous damping model utilized in most system identification procedures may not ac-

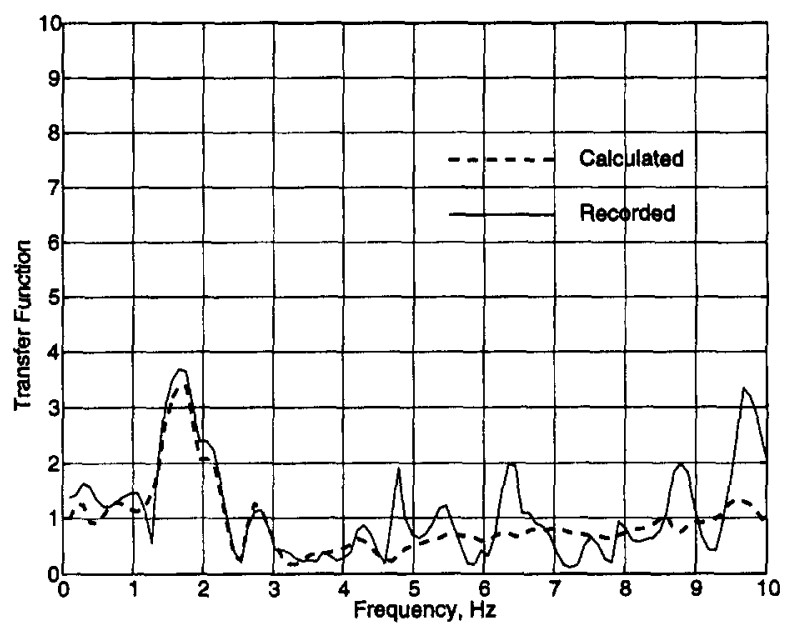

(a)
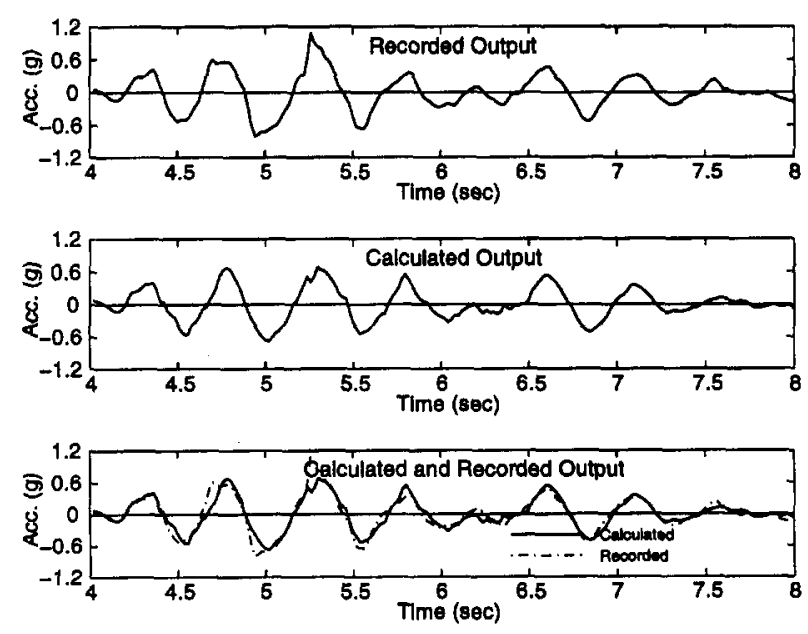

(b)

FIG. 5. Comparison of Response of Identifled Model with Motions Recorded at Channel 4 during Main Shock of 1992 Cape Mendocino/Petrolia Earthquake: (a) Transfer Functions; (b) Time Historles

curately represent complex energy-dissipation mechanisms (e.g., system nonlinearities and joint friction) in actual systems. As a result, different system identification procedures and different initial conditions may lead to significantly different values of the damping ratio. In this investigation the system identification procedure was started with several different initial conditions and that value of the damping ratio was selected which was not sensitive to the initial conditions.

\section{Estimation of Abutment Participation}

The abutment flexibility is an important element in earthquake design of bridges with integral abutments. In particular, a more flexible abutment may lead to higher deformation demands on other lateral-load resisting elements, such as columns in central bent of the PSO bridge. Thus, it may be useful to further investigate the degree of abutment flexibility during earthquakes and how this flexibility affects the earthquake response. For this purpose, an abutment flexibility parameter (AFP) was defined as the ratio of the rigid-body motion and the total motion (including rigid-body and in-plane deformations) at midspan of the deck girder (Fig. 6). The AFP is indicative of the abutment flexibility relative to the deck girder. An AFP of zero indicates rigid abutment and midspan deformation entirely due to in-plane deformation of the deck girder. 


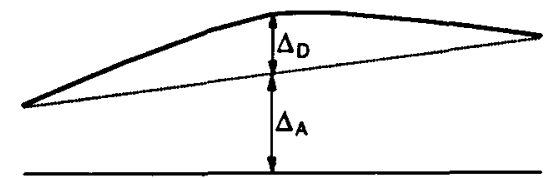

Abutment Flexibility Parameter $=\frac{\Delta_{A}}{\Delta_{A}+\Delta_{D}}$

FIG. 6. Definition of AFP where $\Delta$ is Rigid-Body Motion and $\Delta_{0}$ is Motion Caused by In-Plane Deformation of Road Deck Girder

On the other hand, an AFP of one indicates extremely flexible abutments and midspan deformation entirely due to deformations at abutments with no in-plane deformation in the deck girder. Clearly, abutments are more flexible for higher values of the AFP. As shown previously by Goel and Chopra (1995), abutments become more flexible (or stiffness reduces) because of nonlinear action in the soil enclosed between the wingwalls. Thus, larger values of the AFP are also indicative of larger nonlinear action at abutments.

\section{VIBRATION PROPERTIES DURING EARTHQUAKES}

The transverse vibration properties of the PSO bridge identified from its motions recorded during the six selected earthquakes are presented in Table 2. For the 1992 Cape Mendocino/Petrolia earthquake and its aftershocks, more than one set of vibration properties, corresponding to time windows during which the bridge essentially remained elastic, was identified. However, for the 1986 and 1987 Cape Mendocino earthquakes, only one set of vibration properties was identified because of little variation in the system's behavior during these earthquakes. The identified (or observed) properties included the vibration period, mode shape, and damping ratio. These data were then used to investigate how abutment participation affected the vibration properties of the bridges with integral abutments.

\section{Periods}

The identified periods presented in Table 2 show that the transverse period of the bridge ranged between $0.26 \mathrm{~s}$ (case 10 ) and $0.30 \mathrm{~s}$ (case 8) during the 1986 and 1987 earthquakes. These periods were consistent with the value of $0.28 \mathrm{~s}$ identified by Maroney et al. (1990) using the same earthquakes and $0.27 \mathrm{~s}$ estimated by Gates and Smith (1982) from dynamic tests. The identified periods were slightly longer than the value of $0.22 \mathrm{~s}$ estimated by Gates and Smith (1982) and $0.24 \mathrm{~s}$ by Ventura et al. (1995) based on the ambient vibration testing. Similar observations were made by Werner et al. (1990), based on response of the Meloland Road Overpass during ambient vibration testing, dynamic loading, and the Imperial Valley earthquake.

The bridge period elongated significantly during the 1992 Cape Mendocino/Petrolia earthquake and its aftershocks. The periods identified from motions of the bridge during strong shaking phases of the main event and the first aftershock were $0.57 \mathrm{~s}$ (case 7) and $0.65 \mathrm{~s}$ (case 3), respectively, which are about two times longer than those identified from motions recorded during the previous earthquakes. This indicates that the transverse period of a bridge with integral abutment depends to a large degree on the level of shaking. The peak values of accelerations recorded on the bridge during the main shock of the 1992 earthquake and its first aftershock were 1.09 and $0.76 \mathrm{~g}$, respectively, compared with values of $0.25,0.35$, and $0.33 \mathrm{~g}$ during the two 1986 earthquakes and the 1987 earthquake, respectively (Table 1 ).

The elongation of the transverse period by a factor of about two also indicates that the overall transverse stiffness of the bridge reduced by a factor of four. Because the columns in the central bent of the bridge suffered no damage during these earthquakes, the reduction in stiffness appears to have resulted from a softening of the abutment-soil-pile systems. This observation is consistent with the results presented by Goel and Chopra (1995), which showed that the transverse stiffness of the west abutment during the 1992 earthquake was only about one-fourth the value during the 1986 event.

The results presented in Table 2 also show that the transverse period of the bridge may be different during different shaking phases. During the initial buildup phase of the shaking, the period may be similar to that observed during smaller earthquakes. For example, the period was $0.29 \mathrm{~s}$ (case 4) during the early part of the first aftershock of the 1992 earthquake. However, during the strong shaking phase of the earthquake the period elongates significantly; period values of $0.57 \mathrm{~s}$ (case 7 ), $0.65 \mathrm{~s}$ (case 3 ), and $0.40 \mathrm{~s}$ (case 2) were observed during the 1992 events. As the motion becomes less intense during the later part of the shaking, the period reduces as evidenced by values of $0.35 \mathrm{~s}$ (case 5) and $0.36 \mathrm{~s}$ (case 1) identified from this phase of the 1992 earthquakes.

\section{Damping Ratio}

The damping ratio in the first transverse mode of the PSO bridge ranged from approximately $6 \%$ to approximately $12 \%$ (Table 2). The lower damping values were observed during the smaller earthquakes such as the 1986 and 1987 events. Similar values also were observed during the later phase of the larger earthquakes. However, during the strong shaking phase of the larger earthquakes (the 1992 events) considerably larger values of damping - $8.5 \%$ (case 7 ), $12.1 \%$ (case 3 ), and $9.5 \%$ (case 2)-were observed.

TABLE 2. Vibration Properties of U.S. 101/Painter Street Overpass Identlfied from Recorded Motlons

\begin{tabular}{|c|c|c|c|c|c|c|c|c|}
\hline \multirow[b]{3}{*}{$\begin{array}{l}\text { No. } \\
\text { (1) }\end{array}$} & \multirow[b]{3}{*}{$\begin{array}{c}\text { Earthquake } \\
\text { (2) }\end{array}$} & \multirow{3}{*}{$\begin{array}{c}\text { Time } \\
\text { window } \\
\text { (s) } \\
\text { (3) }\end{array}$} & \multirow{3}{*}{$\begin{array}{l}\text { Period } \\
\text { (s) } \\
\text { (4) }\end{array}$} & \multirow{3}{*}{$\begin{array}{c}\text { Damping } \\
\text { ratio } \\
(\%) \\
(5)\end{array}$} & \multirow{2}{*}{\multicolumn{3}{|c|}{$\frac{\text { MODE-SHAPE COMPONENTS }}{\text { Channel No. }}$}} & \multirow{3}{*}{$\begin{array}{c}\text { Abutment } \\
\text { flexibility } \\
\text { parameter } \\
\text { (9) }\end{array}$} \\
\hline & & & & & & & & \\
\hline & & & & & $\begin{array}{c}9 \\
(6) \\
\end{array}$ & $\begin{array}{c}7 \\
(7) \\
\end{array}$ & $\begin{array}{c}4 \\
(8) \\
\end{array}$ & \\
\hline 1 & Cape Mendocino/Petrolia [Apr. 26, 1992 (AS no 2)] & $13.6-16.4$ & 0.36 & 7.8 & 0.50 & 1.00 & 0.93 & 0.68 \\
\hline 2 & & $6.5-9.5$ & 0.40 & 9.5 & 0.36 & 0.78 & 1.00 & 0.83 \\
\hline 3 & Cape Mendocino/Petrolia [Apr. 26, 1992 (AS no. 1)] & $10.0-13.0$ & 0.65 & 12.1 & 0.79 & 1.00 & 0.98 & 0.87 \\
\hline 4 & & $4.0-6.0$ & 0.29 & $\rightarrow^{a}$ & 0.66 & 1.00 & 0.81 & 0.71 \\
\hline 5 & Cape Mendocino/Petrolia [Apr. 25, 1992 (main event)] & $27.0-30.0$ & 0.35 & 5.6 & 0.44 & 0.93 & 1.00 & 0.73 \\
\hline 6 & & $12.5-15.5$ & 0.36 & 7.0 & 0.55 & 0.96 & 1.00 & 0.78 \\
\hline 7 & & $4.0-8.0$ & 0.57 & 8.5 & 0.67 & 0.89 & 1.00 & 0.91 \\
\hline 8 & Cape Mendocino (Jul. 31, 1987) & $4.0-7.0$ & 0.30 & 6.0 & 1.00 & 0.78 & 0.62 & - \\
\hline 9 & Cape Mendocino [Nov. 21, 1986 (second event)] & $0.0-10.0$ & 0.29 & 6.6 & 0.77 & 1.00 & 0.59 & 0.54 \\
\hline 10 & Cape Mendocino [Nov. 21, 1986 (first event)] & $2.0-4.0$ & 0.26 & - & 0.94 & 1.00 & 0.34 & 0.63 \\
\hline
\end{tabular}

Data not reliable. 
The data presented in Table 2 also shows that higher damping values generally were associated with longer periods. As mentioned previously, longer bridge periods occur because of a softening of abutment-soil-pile systems due to nonlinear soil behavior during the strong shaking phase of the earthquake. This indicates that the additional damping is caused by energy dissipated through nonlinear action at abutment-soil-pile systems. Part of the additional damping also may be caused by radiation and material damping resulting from increased soilstructure interaction.

It is clear from the damping data for the PSO bridge that damping in bridges with integral abutments may be significantly higher than the $5 \%$ value currently used in the bridge design. This is especially so for levels of motion expected during the design earthquake. Also, similar observations have been made by Crouse and Werner (1995) from studies on the Meloland Road Overpass.

\section{Mode Shape}

In addition to the period and damping ratio, the first transverse mode shape of the PSO also was identified (Table 2). The identified mode shape consisted of three components corresponding to transverse motions recorded at three locations on the bridge deck: near the west abutment (channel 4), the central bent (channel 7), and close to the east abutment (channel 9). These components are plotted in Fig. 7 as solid circles for each of the ten cases; mode-shape magnitude at each location is indicated next to the circle. The case number is identified by a bold-faced number on the left side of the plot. The plot also includes the following: (1) A thin, solid line to represent the initial at-rest position of the deck girder; (2) a thin, chained line connecting the mode-shape components at the
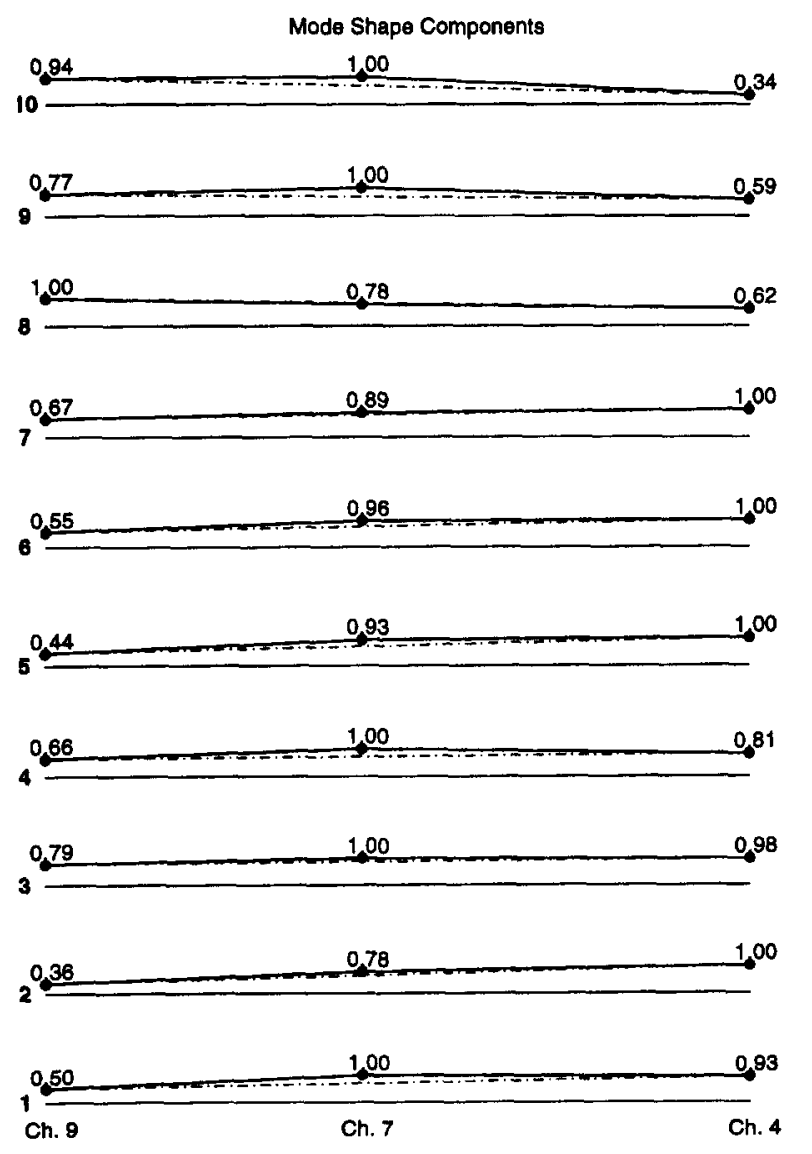

FIG. 7. Transverse Mode Shape Components for PSO Identified from Its Motions Recorded during Actual Earthquake Events locations of channel 4 and 9 to represent the rigid-body component of the mode shape; and (3) a thick, solid line connecting the three circles that represent the mode shape; in reality, the first transverse mode shape would be a smooth curve joining the three circles. Deviation of the solid line from the chained line represents the in-plane deformation component of the mode shape.

Several important trends may be gleaned from the modeshape data. First, significant motions occurred at bridge abutments even though integral abutments may appear to provide considerable restraint in the transverse direction. Such motions may affect deformation demands on other lateral-load resisting elements, such as the columns in the central bent of the PSO bridge. Thus, it is important to properly account for the abutment flexibility (or stiffness) in earthquake analysis of bridges with integral abutments.

Second, in-plane deformation of the deck girder was significant when compared with its rigid-body motion for only low levels of ground shaking, such as during the 1986 earthquakes (cases 9 and 10) or during the later part of the 1992 earthquakes when the motions became small (cases $1,4,5$, and 6). During intense earthquake shaking, the rigid-body motion dominated the mode shape with little or no contribution from in-plane deformation of the deck girder (cases 2, 3, and 7). This indicates that abutments tend to provide much more restraint against transverse movement during low levels of shaking. Thus, stiffness of abutments may be significantly higher during low levels of shaking as compared with high levels. This trend is consistent with the observations made previously by Goel and Chopra (1995).

Finally, the mode-shape component near the east abutment (channel 9) was larger than that near the west abutment (channel 4) for the 1986 and 1987 earthquakes (cases 8-10). However, for this bridge the mode-shape component was expected to be larger at the west abutment because of a thermal expansion joint. The smaller mode-shape component near the west abutment indicates locked condition of the joint during these earthquakes. During the more intense shaking of the 1992 earthquakes, the mode-shape component was larger near the west abutment (cases 1-7). These trends are consistent with the earlier observations based on the peak accelerations recorded during these earthquakes (Table 1).

\section{AFP}

The values of the AFP were computed for the first transverse mode of the PSO bridge and are included in Table 2. Because the mode-shape component at midspan of the deck girder was not available, it was estimated by assuming that in-plane deformation of the deck girder varies as a half-cycle of sine function (Goel and Chopra 1995). The observed values of AFP ranged from 0.54 to 0.91 ; the low value occurred during the lower level of shaking of the second event of the 1986 earthquake (case 9), whereas the high value occurred during the most intense shaking of the bridge during the main event of the 1992 earthquake (case 7). Because higher values of the AFP are associated with more flexible abutments, the presented data indicate that abutments are considerably more flexible during intense earthquake shaking. This observation is consistent with the previous observation based on the bridge periods.

The data also showed significant correlation between the AFP and the damping ratio. In general, higher damping values are associated with larger values of the AFP. Because larger values of the AFP are indicative of higher nonlinear action at abutments, increases in damping may be attributed to the energy dissipated by abutments through inelastic behavior. The correlation between the AFP and damping ratio is further examined in the last section of this paper. 


\section{DESIGN IMPLICATIONS}

The results presented in the preceding section show that transverse vibration properties - period and damping - are affected significantly by the abutment flexibility. In particular, the period elongates and damping increases with increases in the abutment flexibility. As a result it was determined that an investigation into the impact of these changes on design forces and deformations would be useful. An examination of the spectral displacement and pseudoacceleration for observed values of period and damping of the PSO bridge was therefore included in the study.

The spectral quantities were calculated from the 84.1 per-

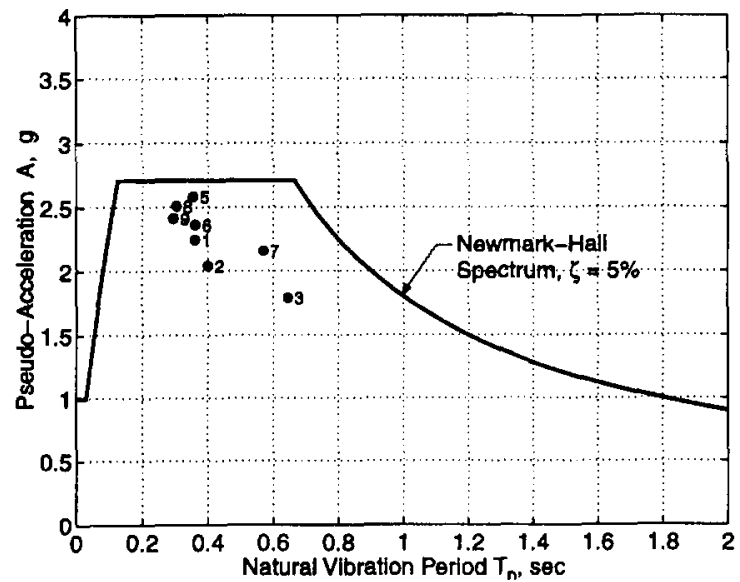

(a)

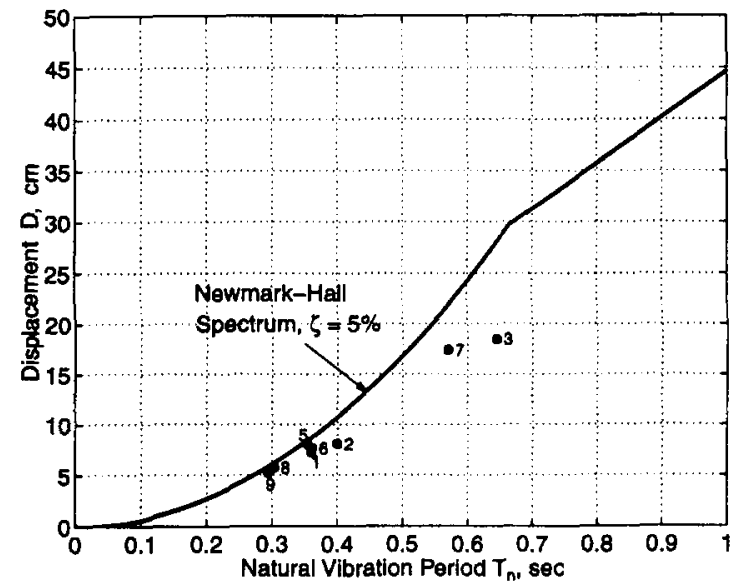

(b)

FIG. 8. Newmark-Hall Spectra $(\xi=5 \%)$ and Spectral Values for Observed Damping and Period of PSO: (a) Pseudoacceleration Design Spectrum; (b) Displacement Design Spectrum centile Newmark-Hall spectrum (Newmark and Hall 1982) with peak ground acceleration $=1 \mathrm{~g}$, velocity $=122 \mathrm{~cm} / \mathrm{s}(48$ in. $/ \mathrm{s}$ ), and displacement $=91.4 \mathrm{~cm}$ (36 in.). The amplification factors for the Newmark-Hall spectrum are $\alpha_{A}=4.38-1.04 \xi$ in the acceleration-controlled region, $\alpha_{V}=3.38-0.67 \xi$ in the velocity-controlled region, and $\alpha_{D}=2.73-0.45 \xi$ in the displacement-controlled region, in which $\xi=$ damping ratio in percent; procedure to construct the design spectrum is available elsewhere (Chopra 1995). The Newmark-Hall design spectrum was selected because it can be constructed for different values of damping ratio. The design spectra specified in most bridge design specifications, for example, the CALTRANS ARS spectra, are only for a $5 \%$ damping ratio.

The design spectrum for a $5 \%$ damping (curve with solid line) and the spectral quantities for the observed period and damping values (solid circles) are shown in Fig. 8. The number next to each solid circle represents the case number listed in Table 2; only those data points are included for which both the period and the damping ratio were identified. The spectral quantities for each case were obtained from the design spectrum constructed for the observed damping. Numerical values of the spectral quantities are listed in Table 3.

The information presented in Fig. 8 and Table 3 was used to evaluate the effects of period elongation and increases in damping. The effects of period elongation were evaluated by examining variation of the $5 \%$ spectra with period; whereas the effects of increased damping were investigated by comparing the spectral quantities from the $5 \%$ spectra with those from spectra for observed values of damping.

\section{Effects of Period Elongation}

The results of this analysis show that elongation of the vibration period does not affect the lateral design force for the PSO bridge. As mentioned previously, the observed vibration period (identified from recorded motions) of the bridge are in the range of $0.29 \mathrm{~s}$ (case 9) to $0.65 \mathrm{~s}$ (case 3). However, this range falls in the acceleration-controlled region of the design spectrum, where pseudoacceleration is independent of the period (Table 3 ). Thus, the design lateral force (mass $\times$ pseudoacceleration) remains unaffected even though the period elongated by a factor of about two. However, for other situations the design force may increase or decrease depending on in which region of the design spectrum the bridge periods fall.

However, the deformation demand on the columns in the central bent of the bridge would increase significantly because of period elongation. This was indicated by an increase in the spectral displacement with period in the acceleration-controlled region (Table 3). For example, the spectral displacement increased by a factor of about five as the period increases from $0.29 \mathrm{~s}$ (case 9) to $0.65 \mathrm{~s}$ (case 3 ); the values of $D$ were 5.8 and $28.0 \mathrm{~cm}$ for the two cases (Table 3). The increase in deformation demand on the column was also indicative of an

TABLE 3. Spectral Displacements and Pseudoaccelerations for U.S. 101/Painter Street Overpass

\begin{tabular}{|c|c|c|c|c|c|c|c|}
\hline \multirow[b]{2}{*}{$\begin{array}{c}\text { Case } \\
(1)\end{array}$} & \multirow{2}{*}{$\begin{array}{c}\text { Period } \\
T \\
(\mathbf{s}) \\
(2)\end{array}$} & \multirow{2}{*}{$\begin{array}{c}\text { Damping } \\
\xi \\
(\%) \\
(3) \\
\end{array}$} & \multicolumn{2}{|c|}{$\begin{array}{c}\text { Pseudoacceleration } \\
A\end{array}$} & \multicolumn{2}{|c|}{$\begin{array}{c}\text { Displacement } \\
D \\
\end{array}$} & \multirow{2}{*}{$\begin{array}{c}\text { Ratio } \\
A \text { or } D(\xi=5 \%) \\
A \text { or } D \text { (observed } \xi) \\
(8)\end{array}$} \\
\hline & & & $\begin{array}{c}\text { Observed } \xi \\
(g) \\
(4)\end{array}$ & $\begin{array}{c}\xi=5 \% \\
(g) \\
(5)\end{array}$ & $\begin{array}{c}\text { Observed } \xi \\
\text { (cm) } \\
(6)\end{array}$ & $\begin{array}{c}\xi=5 \% \\
(\mathrm{~cm}) \\
(7)\end{array}$ & \\
\hline $\begin{array}{l}1 \\
2 \\
3 \\
5 \\
6 \\
7 \\
8 \\
9\end{array}$ & $\begin{array}{l}0.36 \\
0.40 \\
0.65 \\
0.35 \\
0.36 \\
0.57 \\
0.30 \\
0.29\end{array}$ & $\begin{array}{r}7.8 \\
9.5 \\
12.1 \\
5.6 \\
7.0 \\
8.4 \\
6.0 \\
6.6 \\
\end{array}$ & $\begin{array}{l}2.25 \\
2.04 \\
1.79 \\
2.58 \\
2.36 \\
2.16 \\
2.51 \\
2.41\end{array}$ & $\begin{array}{l}2.71 \\
2.71 \\
2.71 \\
2.71 \\
2.71 \\
2.71 \\
2.71 \\
2.71 \\
\end{array}$ & $\begin{array}{r}7.2 \\
8.1 \\
18.5 \\
8.0 \\
7.7 \\
17.4 \\
5.7 \\
5.2 \\
\end{array}$ & $\begin{array}{r}8.7 \\
10.8 \\
28.0 \\
8.4 \\
8.8 \\
21.9 \\
6.2 \\
5.8\end{array}$ & $\begin{array}{l}1.21 \\
1.33 \\
1.51 \\
1.05 \\
1.18 \\
1.25 \\
1.08 \\
1.12\end{array}$ \\
\hline
\end{tabular}


increase in the column force. The column force (column stiffness $\times$ column deformation) increased because of an increase in the column deformation, whereas its stiffness remained essentially unchanged. Postearthquake inspection reports indicated no damage in the columns of the PSO bridge.

In design applications, the foregoing noted effects of period elongation on the earthquake response of the PSO bridge may be included by considering lower and upper bounds on the system period. These bounds may be obtained by considering lower and upper bound on the soil properties that are used in calculating the effective stiffness of abutments.

\section{Effects of Increase In Damping}

Consistent with the expected trends, an increase in damping reduced the design force as well as the deformation demand on the columns (Fig. 8) when compared with their values for $5 \%$ damping. The design force was lower because of a reduction in the pseudoacceleration coefficient and the deformation demand decreased because of a reduction in the spectral displacement (Table 3). Values of the design force and deformation from the $5 \%$ spectra were $25 \%$ (case 7 ) to $50 \%$ (case 3) larger than those from damping observed from motions of the bridge during intense shaking (Table 3 ). Clearly, the 5\% value for damping led to significant overestimation of the design quantities, especially for the levels of ground shaking that are expected during the design earthquake. The foregoing noted effects were smaller during less intense shaking because of a smaller increase in damping.

The beneficial effects of increased damping should be useful for bridge retrofit purposes. Because evaluation of the bridge response for $5 \%$ damping may lead to an overly conservative estimate of demands, such analysis may indicate the need for retrofit. Use of realistic values of damping, such as those observed in this and several other investigations from motions of bridges recorded during earthquakes, may either eliminate or lead to a more economical retrofit. For design of new bridges, however, the increased damping may be assumed to provide an additional factor of safety during strong ground shaking and thus not be incorporated in the design.

\section{Combined Effects}

Elongation in the bridge period increased the deformation and force demands on the columns, whereas increases in damping had the countereffect of decreasing these demands. However, the effect of period elongation dominated the effects of the increased damping. This led to net increases in the deformation and force demands on the columns. As explained previously, these demands increased because of a larger spectral displacement.

\section{EMPIRICAL FORMULAS FOR DAMPING}

As previously noted, there is a significant correlation between the AFP (which is indicative of the abutment participation in earthquake response of bridges) and the damping. This is further apparent from Fig. 9 (solid curves, represent damping from empirical formulas and solid circles represent camping observed in fundamental transverse vibration mode of PSO bridge number next to each solid circle represents the case number in Table 2) were observed values of damping (identified from recorded motions) are plotted against values of AFP. In particular, for values of AFP larger than 0.7, damping increased with increasing AFP. Values of AFP larger than 0.7 are of practical interest because they were observed during strong to intense ground shaking, such as that expected during the design level earthquake.

Although it may be intuitive that damping would increase

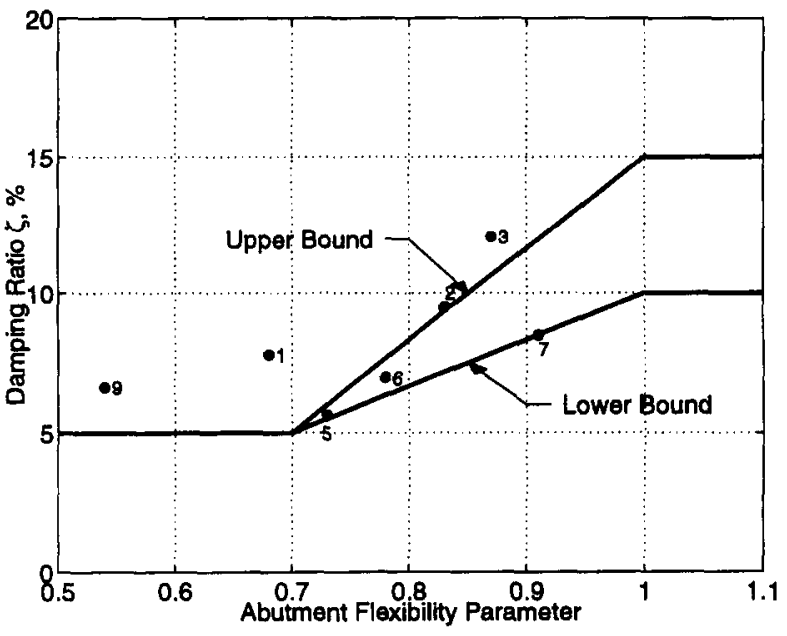

FIG. 9. Variation of Damping with AFP

TABLE 4. Empirical Formulas for Damping Ratio in Bridges with Integral Abutments

\begin{tabular}{c|c|c}
\hline \hline \multirow{2}{*}{$\begin{array}{c}\text { AFP } \\
(1)\end{array}$} & \multicolumn{2}{|c}{ Damping Ratio, $\xi(\%)$} \\
\cline { 2 - 3 } & $(2)$ & $\begin{array}{c}\text { Upper bound } \\
(3)\end{array}$ \\
\hline$<0.7$ & 5 & 5 \\
$0.7-1.0$ & $\left(50 \times\right.$ AFP $\left.^{2}-20\right) \div 3$ & $(100 \times$ AFP -55$) \div 3$ \\
$>1.0$ & 10 & 15 \\
\hline \hline
\end{tabular}

with increasing participation of abutment-soil-pile systems, it may not be easy to develop a theoretical relationship between the damping ratio and the AFP. To overcome this difficulty, data observed from recorded motions were used to develop empirical formulas for estimating damping in the first transverse vibration mode of bridges with integral abutments. Two such formulas for lower and upper bound values of damping are presented in Table 4 and are plotted in Fig. 9 as solid curves. The curves for both bounds start at $5 \%$ damping for AFP $=0.7$. The lower bound and upper bound curves increased linearly to a damping value of 10 and $15 \%$, respectively, at $\mathrm{AFP}=1$.

Although, the empirical formulas presented in Table 4 are similar to the ones proposed earlier by Crouse and Werner (1995) in the sense that the upper limits of lower and upper bound damping values are 10 and $15 \%$, respectively, there are two major differences. First, most of the data used by Crouse and Werner were from dynamic testing of bridges, whereas all the data used in this investigation were from motions of the PSO bridge recorded during actual earthquake events. The damping values identified from motions recorded during intense ground shaking, such as those used in this investigation, are indicative of the values expected during the design level earthquake. However, damping from dynamic testing may be significantly smaller than values observed during strong ground shaking. Second, the abutment participation parameter used by Crouse and Werner included vertical as well as transverse abutment deformations, whereas the parameter used in this investigation included only the transverse abutment deformation. It is believed that the simple parameter used in this investigation is more appropriate because it directly indicates the level of abutment participation in the transverse earthquake response of the bridge.

The AFP, required for estimating damping from the proposed empirical formulas, depends on the bridge response, which in turn depends on the system damping among other factors. Therefore, an iterative procedure should be used to obtain an estimate of the damping from the proposed empirical formulas. 


\section{CONCLUSIONS}

This investigation on vibration properties of the PSO bridge during actual earthquake events has led to the following conclusions:

1. The transverse vibration period and damping ratio of the bridge depended significantly on the level of shaking during the earthquake. In particular, the period elongated and the damping increased as the intensity of shaking increased. The period elongated by a factor of over two whereas the damping increased by $5-10 \%$ during intense shaking, as compared with values observed during low level of shaking and during dynamic testing.

2. The transverse mode shape of the bridge was also dependent on the level of shaking. During intense shaking, the mode shape consisted of primarily the rigid-body motion of the road deck girder, whereas the in-plane motions of the road deck girder dominated the mode shape during low levels of shaking.

3. The data on periods, mode shape, and the AFP all indicated that the abutments provided significant restraint to the bridge movement during low-level shaking. However, during more intense shaking the amount of restraint provided by abutments reduced significantly, such as the reduction by a factor of over four observed for the PSO bridge. Therefore, proper modeling of abutment stiffness is important for estimating earthquake response of bridges.

4. As a result of changes in the vibration properties, deformation and force demands on lateral-load resisting elements other than abutments may increase significantly. It is important to account for such increases in demands in earthquake design of bridges.

5. Damping in modes, which include significant participation of abutments, such as the first transverse mode, may be significantly higher than the $5 \%$ value used in practice. The additional damping may be caused by nonlinear behavior of the soil as well as material and radiation damping from increased soil-structure interaction. The additional damping could be included in the earthquake analysis of bridges to achieve economy, especially in the area of bridge retrofit.

6. Empirical formulas that are developed in this investigation may be used to obtain upper and lower bound values of damping in transverse vibration modes of bridges with integral abutment. These formulas relate the damping ratio and a simple parameter representing the participation of abutments in earthquake response of the bridge.

The preceding conclusions are based on recorded motions of one bridge. Data from other bridges with integral abutments should be useful in verification and further refinement of these conclusions.

\section{ACKNOWLEDGMENTS}

The writer would like to acknowledge the assistance provided by Bob Darragh, Moh-Jiann Huang, Praveen Malhotra, and Anthony Shakal of CSMIP in obtaining the bridge plans and earthquake records. The writer is also thankful to Dr. Praveen Malhotra and Professor Carlos Ventura for their comments on the initial draft of this paper.

\section{APPENDIX. REFERENCES}

American Association of State Highway Transportation Officials-83. (1988). "Guide specifications for seismic design of highway bridges." American Association of State Highway and Transportation Officials, Washington, D.C.

Applied Technology Council. (1981). "Seismic design guidelines for highway bridges." Rep. No. ATC-6, Applied Technology Council, Berkeley, Calif

Beck, J. L. (1978). "Determining models of structures from earthquake records." Rep. No. EERL 78-01, Earthquake Engrg. Res. Lab., California Inst. of Technol., Pasadena, Calif.

CALTRANS. (1991). Seismic design references, bridge design aids, and memos to designers. California Department of Transportation, Sacramento, Calif.

Chopra, A. K. (1995). Dynamics of structures: theory and applications to earthquake engineering. Prentice-Hall, Inc., Englewood Cliffs, N.J.

Crouse, C. B., and Werner, S. D. (1995). "Estimation of modal damping for bridges." Lifeline Earthquake Engineering, Proc., 4th U.S. Conf., Rep.: Tech. Council on Lifeline Earthquake Engrg. Monograph No. 6, ASCE, New York, N.Y., 408-415.

Gates, J. H., and Smith, M. J. (1982), "Verification of dynamic modeling method by prototype excitation." Rep. No. FHWA/CA/SD-82/07, California Dept. of Transp., Offc. of Struct. Design, Sacramento, Calif.

Goel, R. K., and Chopra, A. K. (1995). "Seismic response study of US 101/Painter Street Overpass using strong motion records." Rep. No. CSMIP/95-01, California Dept. of Conservation, Div. of Mines and Geol., Offc. of Strong Motion Studies, Sacramento, Calif.

Goel, R. K., and Chopra, A. K. (1997). "Evaluation of bridge abutment capacity and stiffness during earthquakes." Earthquake Spectra, 13(1), $1-21$.

Li, Y., and Mau, S. T. (1991). "A case study of MIMO system identification applied to building seismic records." Earthquake Engrg. and Struct. Dynamics, 20(11), 1045-1064.

Maroney, B., Romstad, K., and Chajes, M. (1990). "Interpretation of Rio Dell freeway response during six recorded earthquake events." Proc., 4th U.S. Nat. Conf. on Earthquake Engrg., Vol. 1, Earthquake Engrg. Res. Inst., El Cerrito, Calif., 1007-1016.

Newmark, N. M., and Hall, W. J. (1982). Earthquake spectra and design. Earthquake Engineering Research Institute, Berkeley, Calif.

Tsai, N. C., Werner, S. D., and Mahin, S. A. (1993). "Compilation and evaluation of current bridge damping data base." Tech. Rep., Dames and Moore, Oakland, Calif.

Ventura, C. E., Finn, W. D. L., and Felber, A. J. (1995). "Ambient vibration study of the Painter Street overpass." Proc., 7th Can. Conf. on Earthquake Engrg., 787-794.

Werner, S. D., Beck J. L., and Levine, M. B. (1987). "Seismic response evaluation of Meloland Road overpass using 1979 Imperial Valley earthquake records." Earthquake Engrg. and Struct. Dynamics, 15(2), 249-274.

Werner, S. D., Beck, J. L., and Nisar, A. (1990). "Dynamic tests and seismic excitation of a bridge structure." Proc., 4th U.S. Nat. Conf. on Earthquake Engrg., Vol. 1, Earthquake Engrg. Res. Inst., El Cerrito Calif., 1037-1046. 